\title{
Measurement and Correlation of Drop-Size Distribution in Liquid- Liquid Emulsions Formed by High-Velocity Bottom Gas Injection
}

\author{
A. ZAIDI and H. Y. SOHN \\ Department of Metallurgical Engineering, University of Utah, Salt Lake City, UT84112-1183, U.S.A. \\ E-mail:hysohn@mines.Utah.edu
}

(Received on August 12, 1994; accepted in final form on December 16, 1994)

\begin{abstract}
Cold model studies have been carried out to characterize the drop-size distribution in liquid-liquid emulsions formed by bottom gas injection. The emulsion was formed by injecting compressed air through the bottom of a tank containing water and kerosene. A polycondensation technique was used to take samples of the dispersed water drops inside the plume, using a specially designed pneumatic trap. The drop samples were photographed and size analysis was done using an image analysis software.

The drop-size distribution closely obeyed the Gaudin-Schuhmann equation. Correlations have been developed between the drop size distribution characteristics (the Sauter diameter and standard deviation) and appropriate dimensionless numbers characterizing the operating conditions. The experimental conditions covered the industrial range of these dimensionless numbers. Typical drop diameters were in the range of 0.5 to $8 \mathrm{~mm}$. The values of the Sauter diameter were between 4 and $6 \mathrm{~mm}$ and those for the standard deviation were between 0.8 and $1.6 \mathrm{~mm}$.
\end{abstract}

KEY WORDS: drop-size distribution; liquid-liquid emulsions; gas injection; bottom; image analysis system; polycondensation technique; Sauter diameter; smelting reduction process; Q-S coppermaking process.

\section{Introduction}

There exists a general trend towards intensive, higherproductivity processes in the metallurgical industry. To achieve this goal, many new ferrous and nonferrous reactions are carried out in dispersed systems. These include solid particles and/or droplets dispersed in gas as in flash smelting, gas bubbles in liquids as in gas injection metallurgy, solid particles injected into liquids, and liquid-liquid emulsions. Thus, an emulsion of slag and molten metal or matte formed by gas injection is of great importance in many of the new-generation ferrous and nonferrous smelting processes. Notable examples include the in-bath smelting of iron ore being evaluated under the American Iron and Steel Institute (AISI) direct steelmaking research program, the EOF (energy optimizing furnace) steelmaking process, the Q-BOP steelmaking process and the QSL process for lead and copper smelting.

In all of these processes, the formation of an emulsion creates a large interfacial area between the slag and molten metal/matte, resulting in rapid chemical reaction and/or mass transfer between the two phases leading to a highly intensive smelting process. The interfacial area per unit amount of dispersed phase, produced by emulsion formation, depends on the drop-size distribution. The smaller the drops, the larger the interfacial area for a given amount of the dispersed phase. On the other hand, the presence of very small drops leads to problems in phase disengagement which must be achieved after the reaction. Thus, it is important to have an optimum drop-size distribution in the emulsion.

There has been virtually no work on the characterization of drop-size distribution of emulsions formed by high-strength gas injection, although much work has been done on emulsions formed by mechanical agitation.

Frohberg et al. ${ }^{1)}$ studied the drop-size distribution and mass transfer in gas-stirred liquid-liquid systems. The organic phase was the dispersed phase in their system. They found that increasing gas flow rates produce decreasing drop diameters.

Oeters and $\mathrm{Wei}^{2)}$ performed a model test for the emulsification of slag droplets into the metal melt in ladles stirred by bottom gas injection. The number of droplets of slag increased but their average diameter decreased with the stirring-gas flow rate. Since they were studying ladle metallurgy they did experiments for a very low level of slag phase $(10 \mathrm{vol} \%)$ which is much lower than in our experiments $(33-75 \mathrm{vol} \%)$. Their flow rates were 50 to $500 \mathrm{Ncm}^{3} / \mathrm{s}$ which are also low compared to our flow rates $\left(900\right.$ to $\left.4700 \mathrm{Ncm}^{3} / \mathrm{s}\right)$. These differences in experimental conditions accounts for the reverse emulsification (slag dispersed in metal) in their experiments.

Yoshida and Yamada ${ }^{3)}$ measured the average diameter of kerosene drops dispersed in water for a gas agitated liquid-liquid dispersion in vertical tubes. The emulsion was formed by bubbling gas through the bottom of the vertical tube. They correlated the mean drop diameter with the power input per unit mass of liquid and 
dispersed-phase concentration. The average drop size was found to be a function of power input (power input ${ }^{-0.5}$ ) and the volume fraction of oil (volume fraction ${ }^{0.25}$ ).

From the survey of literature, it can be concluded that the relatively moderate amount of work done on the gas stirred liquid-liquid emulsions has been for low flow rates and low slag volumes. It was the objective of this study to characterize the drop-size distribution in gas-stirred liquid-liquid emulsions formed by high strength bottom gas injection for wide ranges of injection rate and the volume fraction of the slag phase which included the industrial range in some of the new and proposed steelmaking and coppermaking processes.

Correlations were developed between the drop-size distribution characteristics (the Sauter diameter or $d_{32}$ and standard deviation of the distribution) and the appropriate operating properties, expressed by suitable dimensionless numbers. The Sauter diameter, $d_{32}$, is defined as:

$$
d_{32}=\frac{\sum\left(n_{i} \cdot d_{i}^{3}\right)}{\sum\left(n_{i} \cdot d_{i}^{2}\right)}
$$

where $n_{i}$ is the number of drops of diameter $d_{i}$. The Sauter diameter was used in this study, since it can be easily related to the interfacial area per unit volume according to the expression:

$$
A=\frac{6 \phi}{d_{32}}
$$

The specific interfacial area, $A$, is important in determining mass transfer rate. Many correlations have been developed in the past ${ }^{4-19)}$ for emulsions formed by mechanical agitation using $d_{32}$ as the characteristic size of the drop. In mechanically agitated systems, the holdup $\phi$ is usually the same as the charged volume fraction of the dispersed phase. In gas-agitated systems, emulsion is formed only within the plume zone, and the holdup of the dispersed phase varies with the axial and radial positions and the operating conditions. The results of a systematic study as well as a comprehensive correlation of the holdup as a function of position and operating variables are presented in another article. ${ }^{20)}$ This paper deals with the size distribution of the dispersed phase.

\section{Experimental Technique}

Cold model studies were carried out in a $1.5 \mathrm{~m}$ long, $0.76 \mathrm{~m}$ wide and $0.76 \mathrm{~m}$ high plexiglas tank placed on a metallic frame. After a thorough literature survey, it was decided to use water and kerosence to represent molten metal (or matte) and slag, respectively. The applicability of water for modeling the steel phase has been shown in an earlier investigation by Kleppe and Oeters, ${ }^{21)}$ based on dimensional analysis. Compressed air was injected through injectors at the bottom of the tank, thus forming an emulsion. A $3.5 \mathrm{~m}$ long cylindrical steel manifold having a diameter of $0.15 \mathrm{~m}$ served as a reservoir for compressed air at a constant pressure. A schematic diagram of the experimental setup is shown in Fig. 1.

A $3.5 \mathrm{~m}$ long cylindrical steel manifold having a diameter of $0.15 \mathrm{~m}$ served as a reservoir for compressed air at a constant pressure. The injectors were made of $2.5 \mathrm{~cm}$ thick acetyl resin formed by the polymerization of formaldehyde (commercially known as Delrin), and had a converging section to accelerate the gas. Injectors with outlet diameters in the range of 0.32 to $0.71 \mathrm{~cm}$ were used. The local gas Mach number could not exceed unity with these injectors because they only had a converging section. Thus, the gas was compressed increasing its density to maintain the mass flow rate at high rates of injection.

A dye was added to the water in the tank to visually differentiate the two liquids (kerosene and water). A specially designed pneumatic trap shown in Fig. 2, was used to take samples. A polycondensation technique was used, for which a monomer called 1-6, hexane-diamine (or hexamethylene diamine) was added to the water in the tank and another monomer called sebacoyl chloride

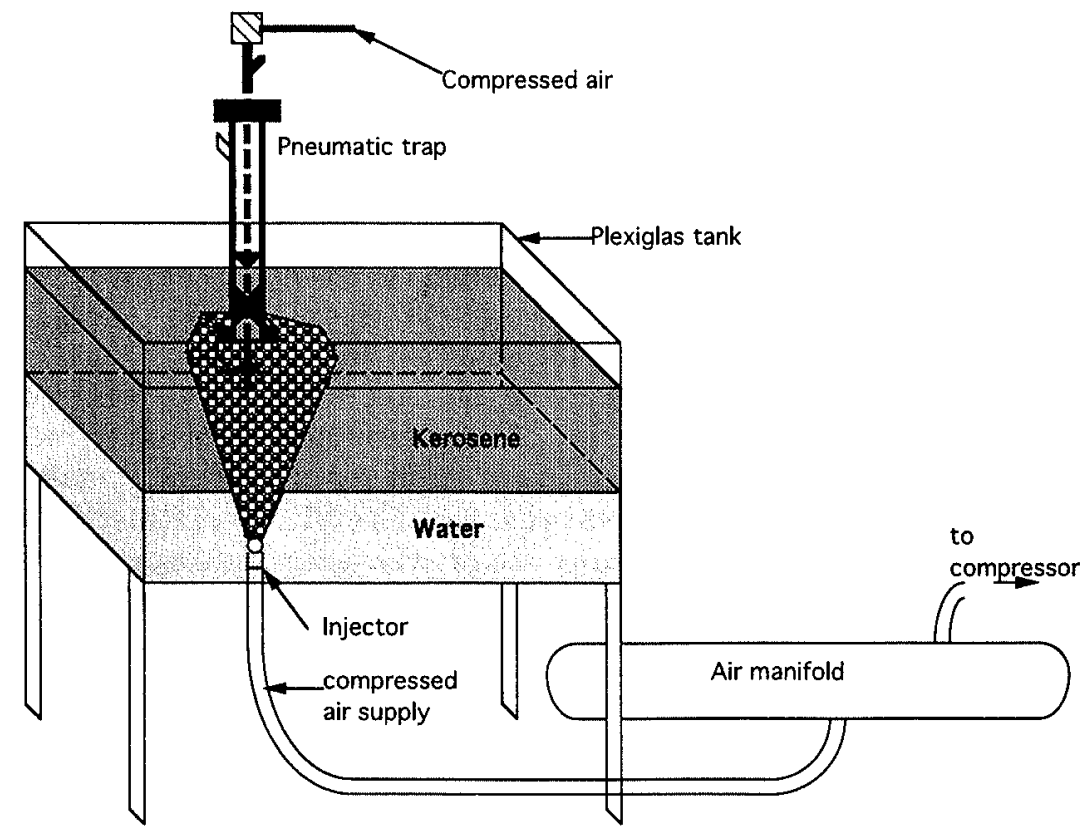

Fig. 1.

Schematic diagram of the experimental apparatus. 


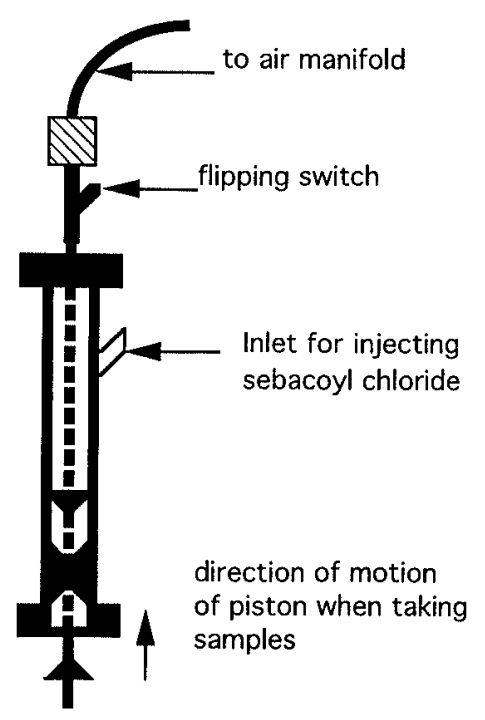

Fig. 2. Schematic diagram of the pneumatic trap.

was injected into the trap. Small quantities of these two were used. As shown in the trap design in Fig. 2, the piston was caused to move up by flipping a switch, drawing a sample of the emulsion into the trap. When the two monomers came into contact, polymerization took place forming a polymer sheath around the water drops. In this way the water drops were frozen. These samples were taken at several locations inside the plume under various experimental conditions. Some kerosene was poured into the petri dishes before the samples were dropped into them. This kerosene increased the separation of the drops to avoid their overlap during the measurement of drop sizes. Back lighting was used for photography to give good contrast between the drops and the surrounding kerosene.

Petri dishes containing the samples were placed on a desk-top light box (for back lighting) and photographs were taken using a Philips* VCM-81 monochrome CCD (closed circuit device) camera with a Philips VS-15R monochrome monitor. An IBM PC based frame grabber was used to digitize these photographs. The light box had an 8 watt fluorescent lamp and an additional thin sheet of translucent nylon was placed on top of it to further diffuse the light. Otherwise, a bright band appeared in the image because of the bright cylindrical lamp. Each photograph was digitized into an image of $512 \times 480$ pixels with 8 bit grayness scale resolution. Each pixel had a digitized luminance intensity signal with a digitized grayness from 0 to 255 . A typical sample image is shown in Fig. 3. Drop size analysis of these images was then done using an image analysis software called Image 1.47 developed by NIH (National Institute of Health). A photograph of a linear scale was first digitized to calibrate the dimensions of the subsequent digitized images. The magnification of the photographs was so adjusted that each pixel was $0.2 \mathrm{~mm}$ in width. Before doing the drop size analysis a background subtraction routine was used to enhance the contrast

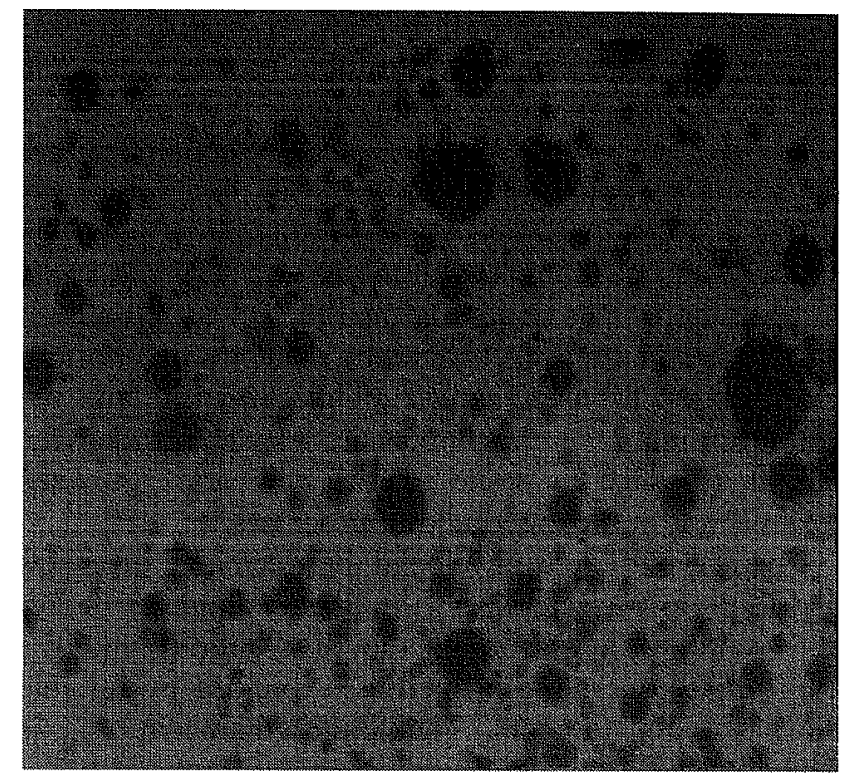

Fig. 3. Typical sample image.

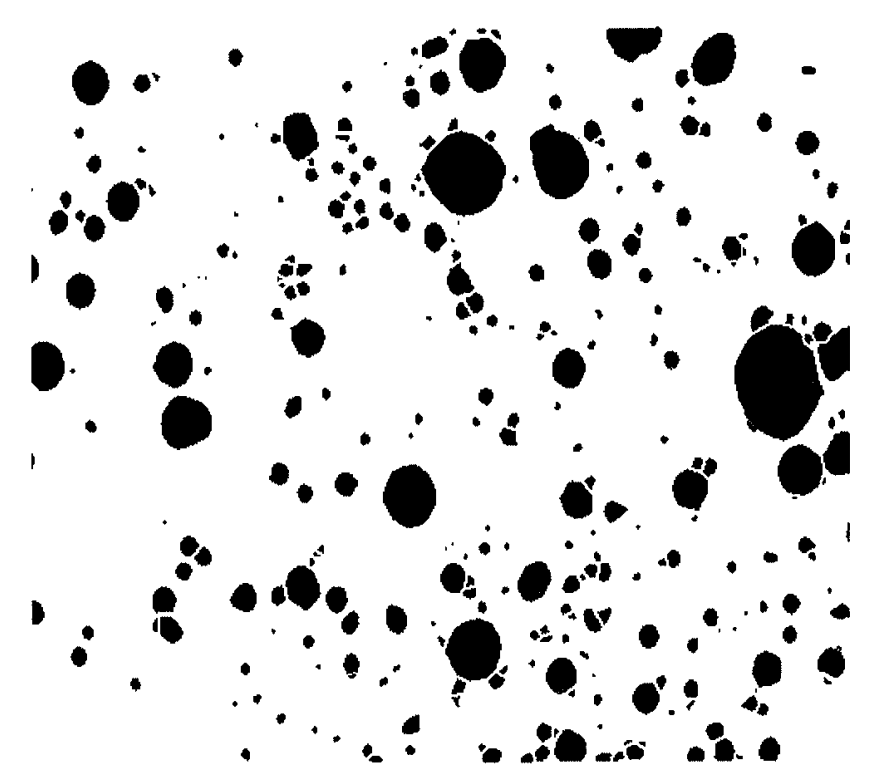

Fig. 4. Typical binary image.

between the drops and the background. After background subtraction, the image was converted into a binary form showing the drops in black and the background in white. The binary image obtained from the image in Fig. 3 is shown in Fig. 4. The area of each drop was measured using a scanning option in the software. Using Microsoft Excel** and assuming spherical drops, the diameter of each of the drops was then calculated. From this data the Sauter diameter and standard deviation of the distribution were determined. When the drops settled on the bottom of the container they became somewhat flat. This effect was corrected by using a correction factor which was determined from experiments. Flattening takes place because of the weight of the drops and is thus a function of drop size. For the drop size range in this work statistically negligible error

\footnotetext{
* Philips Consumer Electronics, Amsterdam, Netherlands.

** Microsoft Excel is a computer software marketed by Microsoft Corporation, Redmond, WA 98052-6399.
} 
Table 1. Ranges of dimensionless numbers for industrial and experimental conditions.

\begin{tabular}{lcc}
\hline & Weber number & $\frac{\rho_{s} h_{s}}{\rho_{m} h_{m}}$ \\
\hline Smelting Reduction Process (AISI) $^{22)}$ & 4000 to 7000 & 1.2 to 2.0 \\
QS Coppermaking Process & & \\
Experimental system in this work & $2.2 \times 10^{5}$ to $3.0 \times 10^{5}$ & 1.1 to 1.7 \\
& 600 to $3.9 \times 10^{5}$ & 0.3 to 2.5 \\
\hline
\end{tabular}

$\rho_{s}:$ density of slag phase

$\rho_{m}:$ density of molten meta $1 /$ matte

$h_{s}$ : bath height of slag phase

$h_{m}$ : bath height of metal/matte phase

Table 2. Ranges of experimental variables in this work

\begin{tabular}{lc}
\hline \multicolumn{1}{c}{ Variable } & Experimental range \\
\hline Flow rate of air & 56 to $280 \mathrm{~N} / / \mathrm{min}$ \\
Injector diameter & 0.32 to $0.71 \mathrm{~cm}$ \\
Height of water & 12.7 to $38 \mathrm{~cm}$ \\
Height of kerosene & 12.7 to $38 \mathrm{~cm}$ \\
\hline
\end{tabular}

occurred when the same correction factor was used for all sizes. The correction factors for different drop sizes were determined by taking photographs of drops suspended in kerosene and then taking another photograph of the drops settled on the bottom of the petri dish (in the flattened form). The drop determined by image analysis were then compared, and a mean correction factor of $0.92( \pm 0.02)$ was obtained.

The Weber number and the ratio of heads (ratio of the products of the densities and bath heights of water and kerosene) were found to be the two important dimensionless numbers in the experiments. In terms of these dimensionless numbers the experiments covered the industrial range of the Smelting Reduction process $(\mathrm{AISI})^{22)}$ and the QS Coppermaking process, ${ }^{23)}$ as shown in Table 1. The ranges of actual experimental variables used in this work to get the desired ranges of dimensionlesses numbers are given in Table 2 . The list of all the values of dimensionless numbers in the experiments along with the corresponding $d_{32}$ and $\sigma$ values is given in Ref. 24).

\section{Results and Discussion}

\subsection{Drop-size Distribution Function}

A typical drop size distribution is shown in Fig. 5. As can be seen in the figure there are a large number of drops in the low size range. But the contribution of small droplets to mass transfer is small because their volume fraction is very low. This can be seen in the volume percent plot for the same sample in Fig. 6.

To correlate the drop size distribution several distribution functions were tested. The Gaudin-Schuhmann distribution function gave the best fit for the drop size data, as shown in Fig. 7. The Gaudin-Schuhmann function is defined as:

$$
F(d)=\left(\frac{d}{d^{*}}\right)^{\alpha}
$$

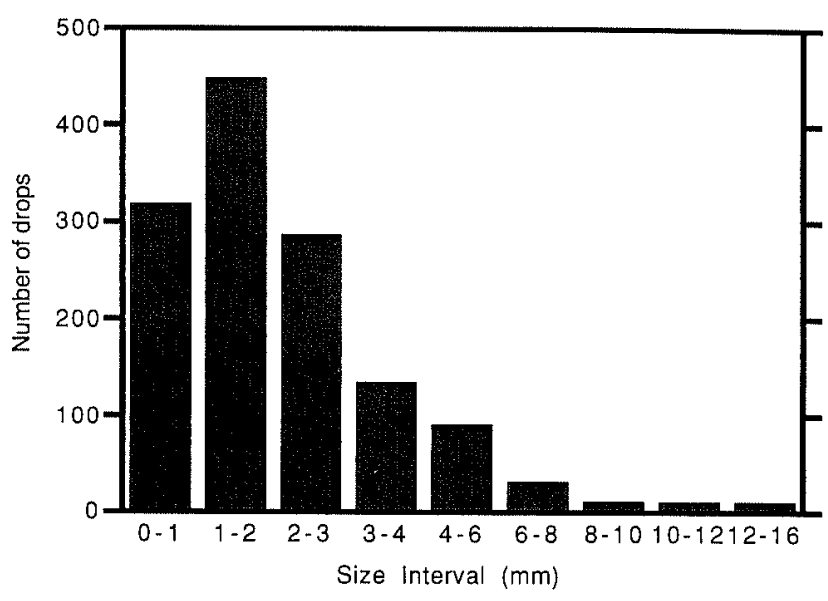

Fig. 5. Typical drop-size distribution.

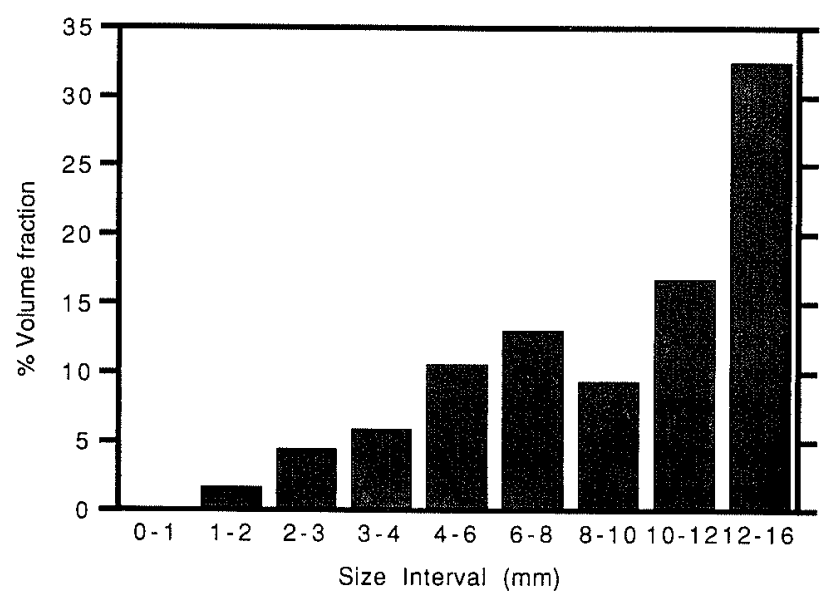

Fig. 6. Volume percent distribution.

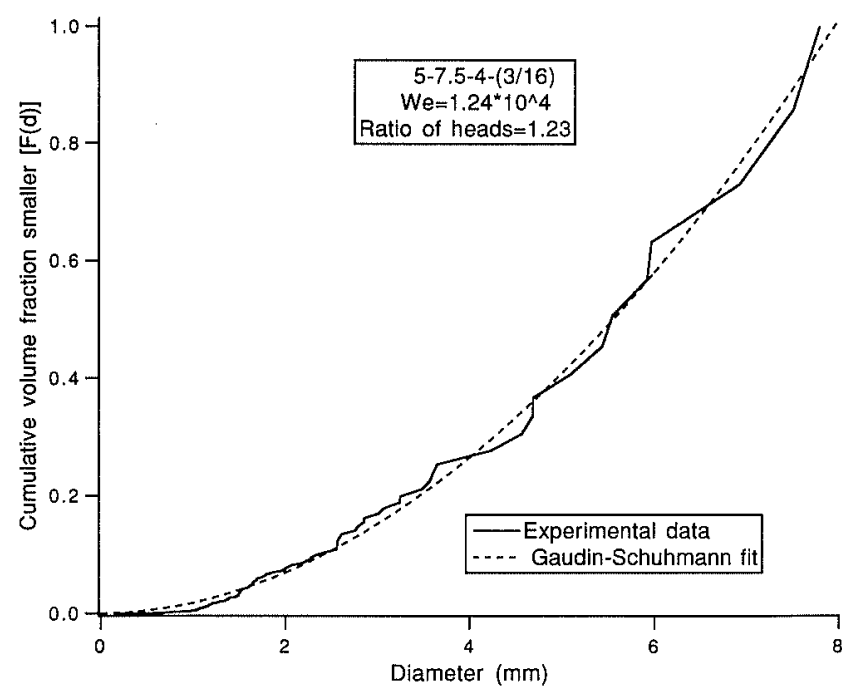

Fig. 7. Typical Gaudin-Schuhmann curve fit for experimental data.

where, $F(d)$ : cumulative volume fraction smaller

$d$ : drop diameter

$d^{*}:$ diameter of the largest drop

$\alpha$ : measure of uniformity.

From the Gaudin-Schuhmann equation, expressions for $d_{32}$ (the Sauter diameter) and standard deviation of the distribution were derived. The values obtained from these expressions were compared with the experimentally 
Table 3. Comparison of experimental and calculated values of $d_{32}$ and $\sigma$.

\begin{tabular}{|c|c|c|c|c|}
\hline \multirow{2}{*}{ Case number } & \multicolumn{2}{|c|}{$d_{32}(\mathrm{~mm})$} & \multicolumn{2}{|c|}{$\sigma(\mathrm{mm})$} \\
\hline & Experimental & Calculated & Experimental & Calculated \\
\hline $5-10-4-3-4-(3 / 16)$ & 4.32 & 4.33 & 1.28 & 1.30 \\
\hline $5-7.5-4-3-6-(1 / 8)$ & 4.97 & 4.83 & 1.60 & 1.63 \\
\hline $5-7.5-3-3-4-(3 / 16)$ & 4.52 & 4.48 & 1.15 & 1.12 \\
\hline $5-10-7-3-4-(3 / 16)$ & 4.36 & 4.31 & 1.43 & 1.42 \\
\hline $5-5-7-3-4-(3 / 16)$ & 5.24 & 5.32 & 1.58 & 1.54 \\
\hline
\end{tabular}

determined values, which yielded a good match between the two, as can be seen in Table 3. This confirmed the validity of using the Gaudin-Schuhmann distribution function to represent our experimental data. The expressions obtained for $d_{32}$ and standard deviation $(\sigma)$ were:

$$
\begin{aligned}
d_{32} & =\left(\frac{\alpha-1}{\alpha}\right) \cdot d^{* \alpha} \cdot \frac{1}{\left[d^{* \alpha-1}-d_{\min }^{\alpha-1}\right]} \\
d_{\min } & =\text { diameter of the smallest drop } \\
\sigma & =\sqrt{\left[\frac{\alpha}{\alpha+2}-\frac{\alpha^{2}}{(\alpha+1)^{2}}\right]} d^{*} \ldots . .
\end{aligned}
$$

\subsection{Variation of $d_{32}$ and $\sigma$ with Dimensionless Numbers}

The variation of $d_{32}$ with distance from the center of the plume and from the interface was investigated but random variation was observed. Thus, the samples from the entire plume (at different depths and different distances from plume centerline) were used to determine these values.

Many dimensionless numbers were tried in an effort to develop the correlation for $d_{32}$ in terms of dimensionless numbers representing the experimental conditions. The Weber number and $\left(\rho_{k} h_{k}\right) /\left(\rho_{w} h_{w}\right)$ (the ratio of the heads of the two phases) were found to have a meaningful relation with $d_{32}$. The Weber number is the ratio of the inertial force to the surface tension force, defined as:

$$
W e=\frac{\rho L V^{2}}{\gamma}
$$

where, $\rho$ : density of injected air

$$
\begin{aligned}
& L: \text { characteristic length } \\
& V: \text { velocity of gas at the exit of injector } \\
& \gamma: \text { interfacial tension. }
\end{aligned}
$$

The characteristic length in our experiments was defined as the diameter of the plume at the original interface between the two phases. For a similar system Iyer ${ }^{23)}$ found that the plume angle was constant with respect to flow rate at 21 degrees. Thus, the characteristic length was a function only of the height of water.

The Sauter diameter initially increases but then decreases with the Weber number, as shown in Fig. 8. Initially, with an increase in the energy input, larger drops of water are carried up into the emulsion. Further increase in the gas flow rate leads to decreasing drop sizes as the excess energy is used to break up the drops. The same trend was observed for different volume ratios

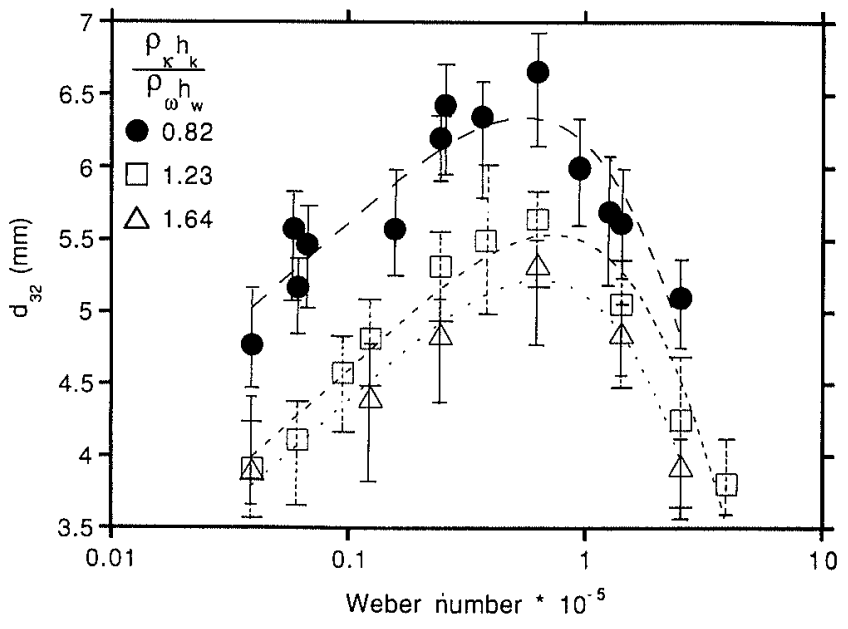

Fig. 8. Variation of $d_{32}$ with Weber number for entire plume.

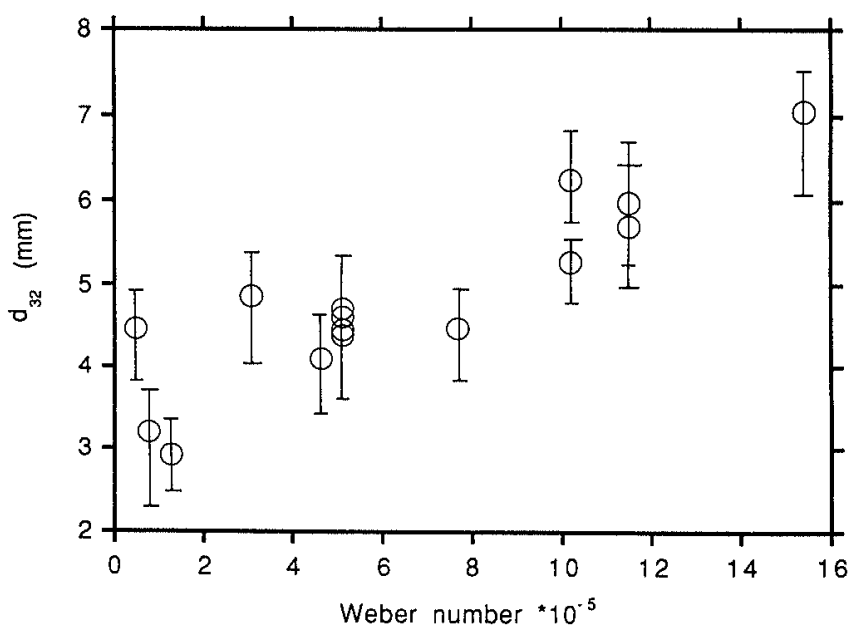

Fig. 9. Variation of $d_{32}$ with Weber number at plume centerline.

of kerosene. The uncertainty ranges shown in this figure indicate the minimum and maximum values of $d_{32}$ within the given sample.

The values of $d_{32}$ for the samples collected along the plume centerline increased monotonically with an increase in energy input, as can be seen in Fig. 9. The values of $d_{32}$ representative of the plume centerline were obtained by combining the data files of samples taken at different depths along the centerline. As the gas flow rate increases, larger chunks of water are carried up along the center of the plume. They contribute to the large value of the average drop size of samples taken at the centerline of the plume. Most of these large chunks of water break up into smaller drops when they hit the 


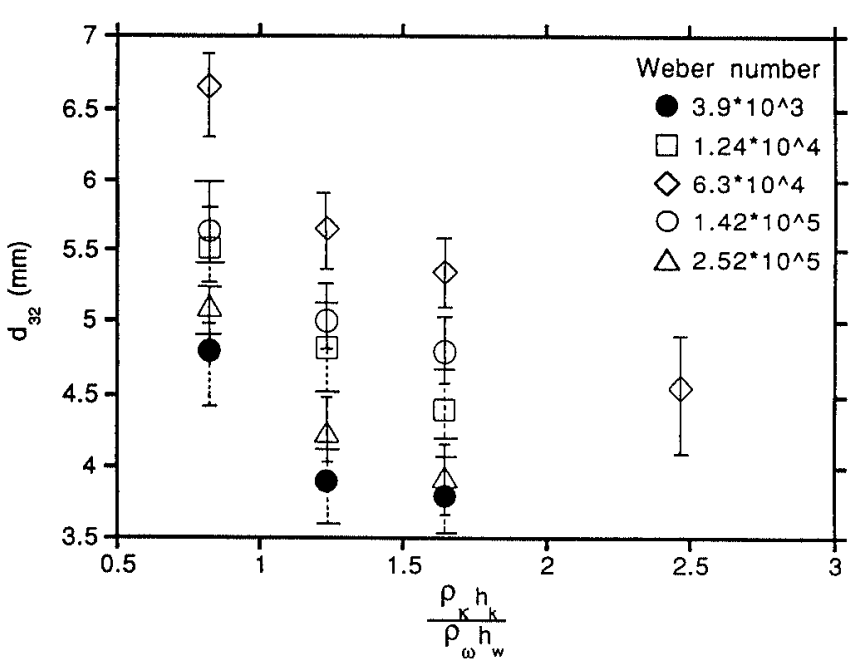

Fig. 10. Effect of the ratio of heads on $d_{32}$ for entire plume.

surface. Those that do not break up still do not show up in the samples taken further away from the centerline, because they settle down very close to the center of the plume due to their weight. For the entire plume, the effect of these large chunks of water is not significant and for high Weber numbers droplet breakup is dominant in determining $d_{32}$ for the entire plume.

Figure 10 shows that $d_{32}$ decreases with an increasing volume fraction of kerosene. As the amount of kerosene increases the concentration of the water drops in the plume decreases (because of the larger plume volume). Thus, the probability of drop coalescence decreases. The same trend was observed for different flow rates and injector diameters in this work. The importance of coalescence in determining the mean drop size has been stressed by Nishikawa et al. $^{25}$ in a study on average drop size in liquid-liquid dispersion. They found that coalescence process is dominant in a dense dispersion because of the increase in probability of collision of drops. Along the plume centerline, however, $d_{32}$ did not vary much with kerosene depth. ${ }^{24}$ In the studies conducted by Frohberg ${ }^{1)}$ and Oeters and $\mathrm{Wei}^{2)}$ the volume fraction of organic phase was very low, so in that case $d_{32}$ would be so large that a stable emulsion of water in kerosene cannot be formed. The aqueous phase cannot be the dispersed phase in such a case, as was observed by these researchers. Besides, they conducted studies for lower gas flow rate for which energy input is not large enough to overcome the larger surface tension of the aqueous phase. The organic phase has lower surface tension and is easily broken up into drops, forming the dispersed phase. In our system the energy input was large enough to break up the water into drops which were carried up into the organic phase to form a stable emulsion.

The standard deviation also initially increases with an increase in the Weber number and starts decreasing after reaching a peak value, as shown in Fig. 11. The initial increase in the Weber number (increasing energy input) causes the formation of larger drops together with smaller ones. This action contributes to an increase in $\sigma$. For a higher Weber number the mean size of the drops starts decreasing because of the dominant breakup action. The

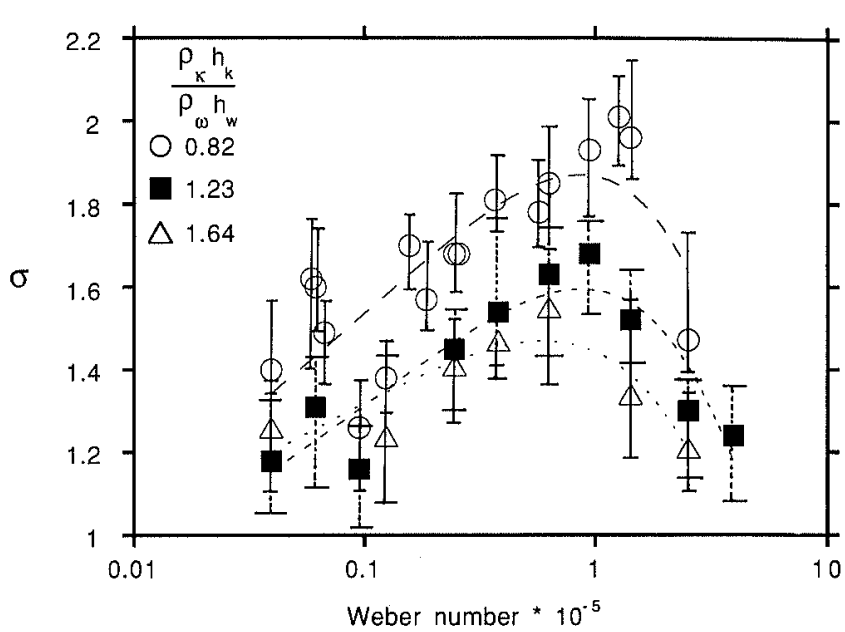

Fig. 11. Variation of $\sigma$ with Weber number for entire plume.

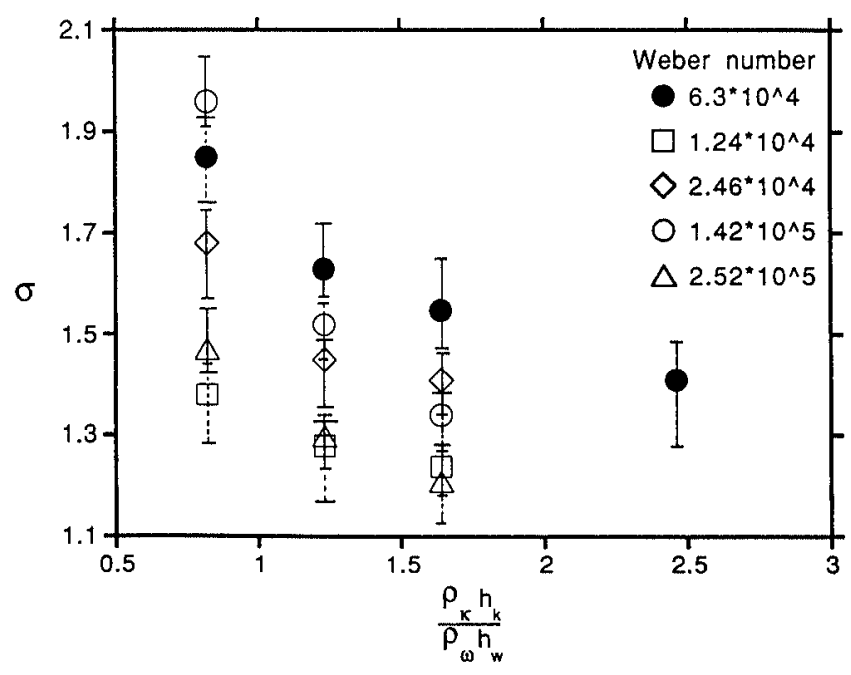

Fig. 12. Effect of the ratio of heads on $\sigma$.

preferential breaking of larger drops causes a shift of the distribution towards the smaller mean size, thus decreasing the spread.

Figure 12 shows that $\sigma$ decreases with an increasing volume of kerosene. This is due to the reduction in the probability of drop coalescence caused by a decrease in the concentration of water drops in the plume, thus suppressing the generation of larger drops. It was determined that, for the same energy input, a critical injector diameter existed which produced a minimum $d_{32}$. To maintain the same energy input, the following condition must hold:

$$
\frac{1}{2} \dot{m} V^{2}=\text { constant }
$$

or

$$
A_{i} V^{3}=\text { constant (since } \rho \text { is constant) }
$$

Using the relationship between volumetric flow rate and linear velocity at the tip of the injector,

$$
\frac{F^{3}}{d_{i}^{4}}=\text { constant }
$$

Thus, the flow rate of gas was increased with injector diameter to keep $F^{3} / d_{i}^{4}$ constant. $d_{32}$ was determined by 


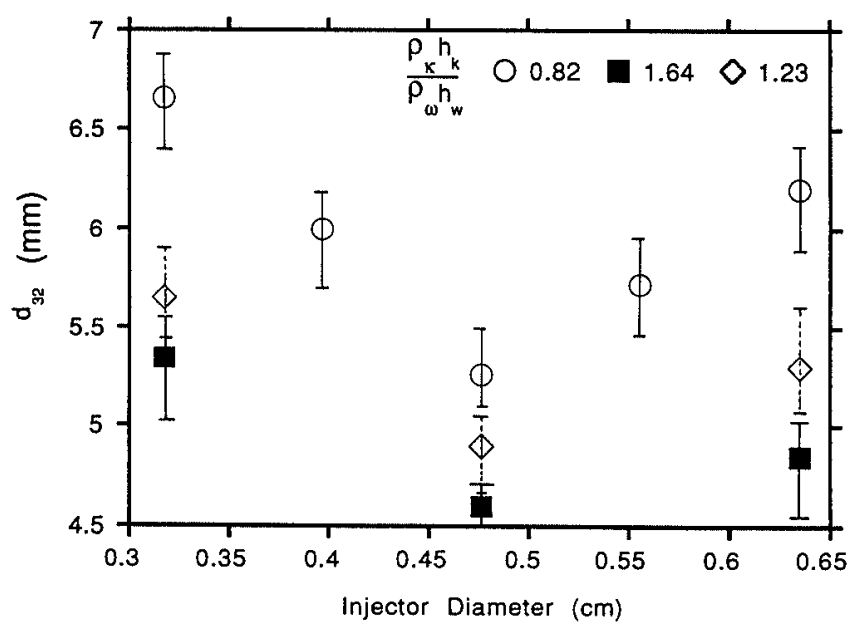

Fig. 13. Critical injector diameter for the same energy input.

varying the injector diameters for different ratio of heads and was found to be minimum for an injector diameter of $0.48 \mathrm{~cm}$ in each case, as shown in Fig. 13 .

\subsection{Correlations for $d_{32}$ and $\sigma$}

Several functional relations between $d_{32}$ and the Weber number were tried to find a correlation. The relation $d_{32}=a W e^{b} \exp (-c \cdot W e)$ gave the best fit for the data, in which $a, b$ and $c$ were parameters to be determined. The curve fitting for different ratio of heads is shown in Fig. 8. As can be seen in the figure we get a good fit for our data considering the width of the uncertainty range. The correlation relating $d_{32}$ to the Weber number and $\rho_{k} h_{k} / \rho_{w} h_{w}$ was determined to be:

$$
d_{32}=a W e^{0.158} \exp (-0.248 \cdot W e)
$$

and

$$
a=7.51\left[\frac{\rho_{k} h_{k}}{\rho_{w} h_{w}}\right]^{-0.24}
$$

The values of all the constants in the correlations are given in Ref. 24).

A similar correlation was developed for $\sigma$ (standard deviation):

$$
\sigma=a^{\prime} W e^{0.135} \exp (-0.171 \cdot W e)
$$

and

$$
a^{\prime}=2.04\left[\frac{\rho_{k} h_{k}}{\rho_{w} h_{w}}\right]^{-0.37}
$$

The curve fitting between $\sigma$ and Weber number for different values of $\rho_{k} h_{k} / \rho_{w} h_{w}$ is shown in Fig. 11 .

The correlation coefficients $(R)$ for these correlations are in the range of 0.82 to 0.91 , which is satisfactory considering the uncertainty range arising from the inherently complex process taking place in bottom gas injection. These correlations can be used in industry to give guidelines for controlling the parameters to obtain a desired drop-size distribution, which affects the mass transfer rate between the metal/matte and slag phases.

Drop-size distribution in liquid-liquid emulsions formed by bottom gas injection has been determined for the first time for high gas flow rates and large volume fractions of slag phase, which are found in new and emerging steelmaking and coppermaking processes. The dimensionless numbers characterizing the flow conditions in the experiments covered the industrial ranges of these processes. The studies done by other researchers have generally been for lower gas flow rates and lower slag volumes, which are typical of ladle metallurgy.

An Image Analysis technique was used for drop size measurements for the first time, which made data acquisition much easier than previously possible. The polycondensation technique of sampling coupled with data acquisition by Image Analysis greatly reduces the error in the determination of drop sizes.

\section{Conclusions}

The drop-size distribution in a liquid-liquid emulsion formed by bottom gas injection obeys the GaudinSchuhmann equation. Typical values of the Sauter diameter and between 4 and $6 \mathrm{~mm}$ and that for standard deviation are between 0.8 and $1.6 \mathrm{~mm}$ for a typical Weber number range of 4000 to $2.0 \times 10^{5}$. The value of the Sauter diameter $\left(d_{32}\right)$ initially increases and then decreases with the Weber number. The value of $d_{32}$ decreases with an increase in the kerosene volume. With respect to the Weber number and the ratio of heads, the standard deviation of the drop-size distribution behaves in the same manner as $d_{32}$. Correlations have been developed for $d_{32}$ and $\sigma$ which will provide a guideline to the industry for controlling the variables affecting the Weber number and the ratio of heads, for the purpose of generating an emulsion with an optimum drop-size distribution in terms of mass transfer area and phase disengagement.

\section{Nomenclature}

$a, a^{\prime}$ : parameters in correlation Eqs. (8) and (10), respectively (mm)

$A:$ interfacial area per unit volume $\left(\mathrm{m}^{-1}\right)$

$A_{i}:$ area of cross section of injector inlet $\left(\mathrm{mm}^{2}\right)$

$d:$ drop diameter $(\mathrm{mm})$

$d^{*}:$ maximum drop diameter $(\mathrm{mm})$

$d_{32}:$ Sauter diameter $(\mathrm{mm})$

$d_{i}:$ injector diameter $(\mathrm{cm})$

$d_{\text {min }}:$ minimum drop diameter $(\mathrm{mm})$

$F$ : volume flow rate of air $\left(\mathrm{Nm}^{3} / \mathrm{s}\right)$

$F(d)$ : cumulative volume fraction smaller

$h_{k}$ : bath height of kerosene $(\mathrm{m})$

$h_{w}$ : bath height of water (m)

$L:$ characteristic length $(\mathrm{m})$

$\dot{m}$ : mass flow rate of air $(\mathrm{kg} / \mathrm{s})$

$V:$ velocity of injected air $(\mathrm{m} / \mathrm{s})$

We: Weber number

Greek letters

$\alpha$ : parameter in Gaudin-Schuhmann distribution function, Eq. (3)

$\gamma:$ interfacial tension $(\mathrm{N} / \mathrm{m})$

$\rho:$ density of injected air $\left(\mathrm{kg} \mathrm{m}^{-3}\right)$

$\rho_{k}:$ density of kerosene $\left(\mathrm{kg} \mathrm{m}^{-3}\right)$

$\rho_{w}:$ density of water $\left(\mathrm{kg} \mathrm{m}^{-3}\right)$

$\sigma:$ standard deviation $(\mathrm{mm})$ 
$\phi:$ holdup fraction, fraction of the plume volume occupied by water drops

\section{Acknowledgments}

This research was supported by the Department of Interior's Mineral Institutes program administered by the Bureau of Mines under grant Nos. G1105129, G1115129 and G1125229. The authors would like to thank the University of Utah Research Committee for awarding one of the authors (A.Z) a Graduate Research Fellowship during the course of this work.

\section{REFERENCES}

1) M. G. Frohberg, F. Gerlach and G. Handschuh: Steel Res., 61 (1990), 151.

2) T. Wei and F. Oeters: Steel Res., 63 (1992), 60.

3) F. Yoshida and T. Yamada: J. Ferment. Tech., 49 (1971), 235

4) F. B. Sprow: Chem. Eng. Sci., 22 (1967), 435.

5) F. B. Sprow: $A I C h E J ., 13$ (1967), 995.

6) C. A. Coulaloglou and L. L. Tavlarides: AIChE J., 22 (1976), 289.

7) J. C. Godfrey, F. I. N. Obi and R. N. Reeve: Proc. Symp. Organized by the Institution of Chemical Engineers at the University of Bradford (U.K.), EFCE (European Federation of Chemical Engineering), Amarousion-Pefki, Greece, (1988), 123.

8) J. O. Hinze: AIChE J., 27 (1955), 289.

9) G. Narsimhan, J. P. Gupta and D. Ramakrishna: Chem. Eng.
Sci., 34 (1979), 257.

10) E. G. Chatzi, A. D. Gavrielides and C. Kiparissides: Ind. Eng. Chem. Res., 28 (1989), 1704.

11) J. B. Fernandes and M. M. Sharma: Chem. Eng. Sci., 22, (1967), 1267.

12) M. T. Chen and S. Middleman: AIChE J., 13 (1967), 989.

13) P. H. Calderbank: Trans. Inst. Chem. Eng., 36 (1958), 443.

14) T. Vermeulen, G. M. Williams and G. E. Langlois: Chem. Eng. Prog., 51 (1953), 85F.

15) R. Shinnar and J. M. Church: Ind. Eng. Chem., 52 (1960), 253.

16) R. Shinnar: J. Fluid Mech., 10 (1961), 259.

17) B. Weinstein and R. E. Treybal: AIChE J., 19 (1973), 304.

18) D. E. Brown and K. Pitt: Chem. Eng. Sci., 29 (1974), 345.

19) V. I. Kiron, K. L. Tavlarides, J. C. Bonnet and C. Tsouris: AIChE $J ., 34$ (1988), 283.

20) M. S. Lee and H. Y. Sohn: Dispersed-Phase Holdup in Liquid-Liquid Emulsions Generated by Bottom Gas Injection, EPD Cong. 1995, ed. by G. W. Warren, TMS, Warrendale, Pennsylvania.

21) W. Kleppe and F. Oeters: Aich. Eisenhüttenwes., 47 (1976), 271.

22) B. Sarma: AISI Direct Steelmaking, Pittsburgh, Pennsylvania, personal communication, (1993).

23) K. Iyer: Ph.D. Dissertation, University of Utah, Salt Lake City, Utah, (1992).

24) A. Zaidi: M. S. Thesis, University of Utah, Salt Lake City, Utah, (1994).

25) M. Nishikawa, F. Mori and S. Fujieda: Journal Chem. Eng. Japan, 20 (1987), 82. 